REVISTA DE DERECHO UNED, NÚM. 17, 2015

\title{
EL FEDERALISMO ARGENTINO Y EL SISTEMA AUTONÓMICO ESPAÑOL: SIMILITUDES Y DIFERENCIAS, CON ESPECIAL REFERENCIA A LOS ESTATUTOS DE AUTONOMÍA
}

\author{
THE ARGENTINE FEDERALISM AND SPANISH AUTONOMIC \\ SYSTEM: SIMILARITIES AND DIFFERENCES, WITH SPECIAL \\ REFERENCE TO THE STATUTE OF AUTONOMY
}

JuAN SANTIAGo YlaRri ${ }^{1}$

Resumen: Hay autores que consideran a España un país federal, aunque nominalmente no lo sea. A su vez, se ha afirmado que si bien muchos países de Latinoamérica, como es el caso de la Argentina, poseen una estructura federal, en la realidad no lo son. El presente trabajo tiene por objeto comparar el sistema federal argentino con el sistema autonómico español. El trabajo se centra de forma particular en la naturaleza jurídica de los Estatutos de Autonomía y su función constitucional. En efecto, los Estatutos de Autonomía son uno de los aspectos más importantes del sistema español que lo diferencian de las constituciones locales o provinciales de los sistemas federales. Asimismo, se analiza la doctrina constitucional que surge de la STC 31/2010 y su recepción en la doctrina.

Abstract: Some authors consider Spain a federal country, although nominally it is not. Also, it has been argued that while many Latin American countries, as is the case of Argentina, have a federal structure, in fact they are not. This paper aims to compare the Argentine federal system with the Spanish autonomic system. The work focuses in particular on the legal nature of the Statute of Autonomy Aires.

${ }^{1}$ Doctorando y profesor de Derecho Constitucional en la Universidad de Buenos 
and its constitutional role. Indeed, the Statutes of Autonomy are one of the most important aspects of the Spanish system that differentiate it from the local or provincial constitutions of the federal systems. Also, the paper analyzed the constitutional doctrine that emerges from the STC 31/2010 and its reception in doctrine.

Palabras clave: Federalismo; sistema federal argentino; sistema autonómico español; Estatutos de Autonomía.

Keywords: Federalism; Argentine federal system; Spanish autonomic system; Statutes of Autonomy.

Recepción original: 20/08/2015

Aceptación original: 2/09/2015

Sumario: I. Introducción. II. El federalismo y las características del sistema argentino. III. El sistema autonómico español. IV. La naturaleza jurídica de los estatutos de autonomía; IV. A. Los Estatutos de Autonomía como «norma institucional básica» y como «ley orgánica»; IV. B. El contenido de los Estatutos de Autonomía; IV. C. Los Estatutos de Autonomía como normas funcionalmente constitucionales; IV. D. Los Estatutos de Autonomía en la STC 31/2010. V. Conclusiones.

\section{INTRODUCCIÓN}

Hay autores que consideran a España un país federal, aunque nominalmente no lo sea. A su vez, se ha afirmado que si bien muchos países de Latinoamérica, como Argentina, Brasil y Venezuela poseen una estructura federal, en la realidad no lo son. En este contexto, el presente trabajo tiene por objeto comparar el sistema federal argentino con el sistema autonómico español, prestándose particular atención a los Estatutos de Autonomía y a la doctrina constitucional que surge al respecto de la STC 31/2010, de 28 de junio.

En primer lugar, se efectuarán unas breves consideraciones sobre el federalismo y, en particular, del sistema federal argentino. Luego, se analizará el sistema autonómico español y la naturaleza jurídica de los Estatutos de Autonomía, para concluir con unas consideraciones personales sobre el tema objeto de análisis. 


\section{EL FEDERALISMO Y LAS CARACTERÍSTICAS DEL SISTEMA ARGENTINO}

$\mathrm{Al}$ federalismo se lo puede definir desde diversos puntos de vista, como el político, el jurídico y el social. En efecto, se ha dicho que el federalismo es una forma de gestión política de las sociedades modernas que desde el punto de vista político, hace que sea posible combinar las aspiraciones de los socios a la autonomía, la separación y la libertad, con sus deseos de unidad, la solidaridad y la interdependencia. Desde el punto de vista jurídico, un Estado federal está anclado en el principio de la puesta en común de la soberanía y las competencias legislativas entre dos órdenes de gobierno autónomos, ninguno de los cuales está subordinado al otro. En el plano social, la sociedad federal se desarrolla tanto desde el reconocimiento de la pluralidad como de la heterogeneidad de la sociedad ${ }^{2}$.

El sistema federal de Estados Unidos de finales del siglo XVIII, ha sido aplicado con posterioridad en diversas sociedades básicamente «mononacionales» como Argentina, Australia, Austria, Brasil y Alemania $^{3}$. Refiriéndose al Estado federal, MADISON señalaba que constituye un buen término medio entre los intereses nacionales y locales. En efecto, sostuvo que

${ }^{2}$ LAFOREST, Guy; CARON, Jean-François. «Contemporary Challenges and Usefulness of Federalism» en LAFOREST, Guy (dir.), Interpreting Quebec's exile within the federation, PIE Peter Lang, Bruselas, 2014, págs. 31-37.

Asimismo, sobre el principio federal, Kennett Clinton WHEARE ha señalado que "consiste en dividir los poderes de forma que el gobierno general y los gobiernos regionales estén cada uno, dentro de una esfera, coordinados e independientes». Citado por BLANCO VALDÉS, Roberto L. Los rostros del federalismo, Alianza, Madrid 2012, pág. 21, quien realiza un excelente estudio comparado de diversos sistemas federales existentes, entre los que se encuentran España y Argentina.

Por otra parte, cabe resaltar el trabajo de EATON, quien realiza una comparación de la visión del federalismo de cuatro autores, analizando el concepto, las causas y las consecuencias del federalismo. El autor resalta que el estudio del federalismo se beneficiaría si se prestara una mayor atención a las cuestiones de fortaleza institucional que a las del diseño institucional, así como una mayor consideración sistemática de factores no institucionales, como los grupos de interés, la formación de identidades, y las presiones internacionales (EATON, Kent. «Federalism in Europe and Latin America: Conceptualization, causes, and consequences», World Politics, Vol. 60, julio 2008, pág. 692).

${ }^{3}$ WATTS, Ronald L. "Comparative reflections on federalism and democracy», en BURGEES, Michael; GAGNON Alain G., Federal democracies, Routledge, Londres, 2010, pág. 330. Por el contrario, el autor señala que Bélgica, Canadá, India y España representan ejemplos multinacionales de los esfuerzos para establecer una organización de tipo federal o federal. Sin embargo, cabe destacar que el artículo 75, inc. 17 $\mathrm{CA}$ ha reconocido «la preexistencia étnica y cultural de los pueblos indígenas argentinos». 
ampliando mucho el número de los electores, se corre el riesgo de que el representante esté poco familiarizado con las circunstancias locales y con los intereses menos importantes de aquéllos; y reduciéndolo demasiado, se ata al representante excesivamente a estos intereses, y se le incapacita para comprender los grandes fines nacionales y dedicarse a ellos. En este aspecto la Constitución federal constituye una mezcla feliz; los grandes intereses generales se encomiendan a la legislatura nacional, y los particulares y locales a la de cada Estado ${ }^{4}$.

Cabe referirnos ahora de forma particular al sistema federal argentino ${ }^{5}$, teniendo en cuenta los cambios en el sistema incorporados en la reforma constitucional de $1994^{6}$, para luego diferenciarlo del sistema autonómico español. Para ello, se acudirá a las normas Constitucionales, la jurisprudencia de la Corte Suprema ${ }^{7}$ y la doctrina.

El Preámbulo de la Constitución Argentina (en adelante CA) en su primera parte señala: «Nos los representantes del pueblo de la

${ }^{4}$ HAMILTON, Alexander; MADISON, James; JAY, John. El Federalista, Fondo de Cultura Económica, México, 2001, N 10.

${ }^{5}$ En relación a los aspectos históricos del federalismo argentino, ver FRÍAS, Pedro J., El proceso federal argentino, El Copista, Córdoba, 1998; y HERNÁNDEZ, Antonio María, dir., Aspectos históricos y políticos del federalismo argentino, Academia Nacional de Derecho y Ciencias Sociales de Córdoba, Córdoba, 2009. Asimismo, sobre la influencia del pensamiento de Alberdi en el sistema federal argentino, ver HARO, Ricardo. «Una perspectiva del pensamiento federalista alberdiano. Celebrando el $150^{\circ}$ aniversario de la publicación de las Bases el $1 .^{\circ}$ de mayo de 1852 en Valparaíso», Microjuris, Doctrina, MJ-DOC-1979-AR, 2003.

${ }^{6}$ Más allá de las consideraciones que efectuarán más adelante, se has dicho que las principales reformas introducidas en 1994 son: el carácter contractual más que estático del actual federalismo de concertación; una mayor solidaridad federal en coparticipación e igualdad de oportunidades; los convenios internacionales que no afecten la política exterior ni el crédito público de la Nación, con conocimiento del Congreso; la creación de regiones; y la autonomía del régimen municipal, a reglar por cada provincia (RODRÍGUEZ GALÁN, Alejandra. «El sistema federal argentino: avances y retrocesos», Foro Global Digital sobre Descentralización: Retos de la democracia del futuro, ponencia, Venezuela, 2007). Asimismo, sobre la incidencia de la reforma constitucional en el sistema federal, ver las obras de HERNÁNDEZ, Antonio María. Federalismo, autonomía municipal y ciudad de Buenos Aires en la reforma constitucional de 1994, Depalma, Buenos Aires, 1997; HERNÁNDEZ, Antonio María. Federalismo y Constitucionalismo Provincial, Abeledo-Perrot, Buenos Aires, 2009; y SABSAY, Daniel Alberto. "El federalismo argentino. Reflexiones luego de la reforma constitucional», en AGULLA, Juan Carlos, comp. Ciencias Sociales: Presencia y Continuidades, Academia Nacional de Ciencias, Buenos Aires, 1999, págs. 425-438.

${ }^{7}$ En relación a los principales precedentes de la Corte Suprema en relación al federalismo, ver MANILI, Pablo L., dir., Máximos Precedentes. Corte Suprema de Justicia de la Nación. Derecho constitucional, 1. ${ }^{\circ}$ ed., La Ley, Ciudad Autónoma de Buenos Aires, 2013, t. IV, págs. 593-774. 
Nación Argentina, reunidos en Congreso General Constituyente por voluntad y elección de las provincias que la componen (...) ordenamos, decretamos y establecemos esta Constitución, para la Nación Argentina». Es decir, que las provincias argentinas son previas a la creación del Gobierno federal. Sobre el particular, la Corte Suprema ha señalado que la Constitución «ha fundado una unión indestructible pero de estados indestructibles» ${ }^{8}$. En su artículo $1^{\circ}$, la Constitución establece que la Nación Argentina «adopta para su gobierno la forma representativa republicana federal». Mientras que la primera parte de la Constitución se dedica a las «declaraciones, derechos y garantías», la segunda parte se refiere a las «autoridades de la Nación». Esta última, se divide en dos grandes títulos: el primero dedicado al «Gobierno Federal» y, el segundo, a los «Gobiernos de Provincia».

El artículo 5 CA refiere que cada provincia debe dictar para sí una Constitución bajo el sistema representativo republicano y de acuerdo con los principios, declaraciones y garantías de la Constitución nacional. Asimismo estipula que para que el Gobierno federal garantice a cada provincia el goce y ejercicio de sus instituciones, las provincias deben asegurar su administración de justicia, su régimen municipal, y la educación primaria ${ }^{9}$. De modo complementario, el artículo $123 \mathrm{CA}$ establece que las constituciones provinciales deben asegurar la autonomía municipal «reglando su alcance y contenido en el orden institucional, político, administrativo, económico y financiero ${ }^{10}$. Al respecto la Corte Suprema ha señalado que el Poder Constituyente provincial, pertenece al ámbito de la autonomía local $\mathrm{y}$, en consecuencia, integra la zona de reserva de facultades no delegadas. Por lo tanto, el procedimiento de reforma de las constituciones locales ha quedado sustraído al control político del gobierno central $^{11}$. Sobre el artículo 5 antes citado, el máximo tribunal se ha

${ }^{8}$ CSJN. «Bressani Carlos H. y otros c/ Provincia de Mendoza» 2/6/1937, Colección de Fallos de la Corte Suprema de Justicia de la Nación, t. 178, pág. 9.

${ }^{9}$ En relación al control de constitucionalidad de la garantía federal, ver BIANCHI, Alberto B., Control de constitucionalidad, $3^{\circ}$ ed., Abaco, Ciudad de Buenos Aires, 2002, t. I, págs. 216-224.

${ }^{10}$ En la reforma constitucional de 1994, al clásico sistema de organización nacional de federación, provincia y municipio, fue incorporada la Ciudad de Buenos Aires. Si bien tiene numerosos coincidencias con una provincia, los cierto es que, respecto a su estatus, el magistrado de la Corte Suprema Vázquez, la definió como «un verdadero engendro definido como plan, designio u obra intelectual mal concebidos» (CSJN. «Partido Justicialista - Distrito Capital Federal s/ acción declarativa de certeza», 29/4/2003, Fallos: 326:1481, voto del ministro Vázquez, considerando 4).

${ }^{11}$ CSJN. «Brandi, Eduardo Alberto c/ Mendoza, Provincia de s/ acción de amparo», 27/9/2005, Fallos: 328:3573. 
expedido en un caso reciente, señalando que si bien el aquel precepto declara la unidad de los argentinos en torno del ideal republicano, lo hace con arreglo a la diversidad proveniente de la organización federal en cuanto encierra un reconocimiento y respeto hacia las identidades de cada provincia, que encuentra su campo de realización dentro del ámbito comprendido por los poderes no delegados al Gobierno de la Nación y también en el de la adecuación de sus instituciones. Asimismo, con cita de una obra clásica de Joaquín V. GONZÁLEZ, destacó que la necesidad de armonía entre los estados particulares y el Estado nacional

debe conducir a que las constituciones de provincia sean, en lo esencial de Gobierno, semejantes a la nacional; que confirmen y sancionen sus principios, declaraciones y garantías, y que lo modelen según el tipo genérico que ella crea. Pero no exige, ni puede exigir que sean idénticas, una copia literal o mecánica, ni una reproducción más o menos exacta e igual de aquélla. Porque la Constitución de una Provincia es un código que condensa, ordena y da fuerza imperativa a todo el derecho natural que la comunidad social posee para gobernarse, a toda la suma de soberanía inherente, no cedida para los propósitos más amplios y extensos de fundar la Nación. Luego, dentro del molde jurídico del código de derechos y poderes de ésta, cabe la más grande variedad, toda la que pueda nacer de la diversidad de caracteres físicos, sociales e históricos de cada región o provincia, o de sus particulares anhelos o aptitudes colectivos ${ }^{12}$.

Asimismo, la Corte Suprema debe controlar que las constituciones provinciales se adecúen al sistema de derechos de la Constitución. En este contexto, sostuvo en un caso que el artículo 177 de la Constitución de la Provincia de Buenos Aires, en cuanto exigía para ser juez de una Cámara de Apelaciones «haber nacido en territorio argentino o ser hijo de ciudadano nativo si hubiese nacido en país extranjero", era manifiestamente contraria a la Ley Fundamental, toda vez que lesionaba el principio de igualdad consagrado en ella, y excedía las limitaciones que prescribe para ejercer idénticos cargos en el orden nacional, a los que aspiraba el recurrente ${ }^{13}$.

En lo que respecta a las instituciones provinciales, el artículo 122 $\mathrm{CA}$ indica que las provincias «se dan sus propias instituciones locales y se rigen por ellas. Eligen sus gobernadores, sus legisladores y demás funcionarios de provincia, sin intervención del Gobierno federal». Sobre este precepto, el máximo tribunal ha señalado que no le incum-

${ }^{12}$ CSJN. «Colegio de Abogados de Tucumán c/ Honorable Convención Constituyente de Tucumán y otro», 14/4/2015, Fallo CSJ 22/2009 (45-C), considerando 14.

${ }^{13}$ CSJN. «Hooft, Pedro Cornelio Federico c/ Buenos Aires, Provincia de s/ acción declarativa de inconstitucionalidad», 16/11/2004, Fallos: 327:5118. 
be discutir la forma en que las provincias organizan su vida autóno$\mathrm{ma}^{14}$. Cabe aclarar que los gobiernos de provincia no sólo ejercen las potestades ejecutivas y legislativas, siempre en el ámbito de sus competencias, sino también la judicial ${ }^{15}$.

Por otro lado, el artículo $121 \mathrm{CA}$ señala que las provincias «conservan todo el poder no delegado por esta Constitución al Gobierno federal $»^{16}$. De forma complementaria, el artículo $126 \mathrm{CA}$ establece que «las provincias no ejercen el poder delegado a la Nación». De este modo, se ha dicho que la delegación es hecha por las provincias a través de la Constitución como instrumento originario de formación y estructura de la federación ${ }^{17}$. La Corte Suprema sostiene habitualmente que los poderes de las provincias son originarios e indefinidos

${ }^{14}$ CSJN. «Córdoba s/ recurso de apelación y nulidad», 13/11/2007, Fallos: 330:4797.

${ }^{15}$ En particular sobre la visión del Poder Judicial dentro del sistema federal, ver BROGDON (2013).

${ }^{16}$ Esta previsión constitucional es muy similar a la Enmienda X de la Constitución norteamericana que señala que "Los poderes que la Constitución no delega a los Estados Unidos ni prohíbe a los Estados, queda reservados a los Estados respectivamente o al pueblo». Sobre la interpretación de este precepto, la Suprema Corte norteamericana ha ido variando en el tiempo su postura. En el precedente «National League of Cities v. Usery» de 1976 (426 U. S. 833), el tribunal sostuvo que se podía establecer una distinción entre las competencias entre el gobierno federal y los gobiernos locales. El criterio era el de las funciones gubernamentales tradicionales («traditional governmental functions»). Dicha postura cambió con el caso «García v. San Antonio Transit Auth.» de 1985 (469 U. S. 528) en la que se señaló que el criterio de «funciones gubernamentales tradicionales» era no sólo impracticable, sino también inconsistente con los principios del federalismo. Asimismo, se sostuvo que la protección de la soberanía de los estados debía ser defendida a través del proceso político y no por el control judicial. Sin perjuicio de ello, el tribunal modificó en cierto sentido su posición en el caso «New York v. United States» de 1992 (505 U. S. 144), en el que se destacó que las instituciones políticas podrían no servir plenamente a una adecuada protección contra una actuación federal contraria a la soberanía de un Estado parte. Sobre esta cuestión, ver TRIBE, Laurence H. American Constitutional Law, 3. ${ }^{\circ}$ ed., Foundation Press, New York, 2000, págs. 860-903; y CHEMERINSKY, Erwin, Constitutional law: principles and policies, $4^{\circ}$ ed, Wolters Kluwer Law and Business, New York, 2011, págs. 304-318. En la doctrina argentina, ver SOLA, Juan V. Manual de Derecho Constitucional, La Ley, Buenos Aires, 2010, págs. 320-324.

No es en vano citar en este punto al debate efectuado en Estados Unidos, en tanto, como lo ha señalado un magistrado de la Corte Suprema argentina «la Constitución de la República Argentina tuvo por modelo formal a la Constitución de los Estados Unidos, lo que otorga enorme significación la jurisprudencia de la Suprema Corte de los Estados Unidos...» (CSJN. «Menem, Carlos Saúl c/ Editorial Perfil S. A. y otros s/ daños y perjuicios-sumario», 25/9/2001, Fallos: 324:2895, voto del doctor Vázquez, considerando 12).

${ }^{17}$ BIDART CAMPOS, German J. Manual de la Constitución Reformada, Ediar, Buenos Aires, 2000, t. I, pág. 440. 
y los delegados a la Nación definidos y expresos ${ }^{18}$, aunque aquellos poderes provinciales no pueden enervar el ejercicio razonable de los poderes delegados al Gobierno federal «so pena de convertir en ilusorios los propósitos y objetivos de las citadas facultades que fincan en la necesidad de procurar eficazmente el bien común de la Nación toda, en el que necesariamente se encuentran engarzadas y del cual participan las provincias» ${ }^{19}$. Sin embargo, cabe señalar que al igual que en Estados Unidos, en la Argentina la cláusula residual se ha invertido. Como bien señala ARAGÓN REYES, esta situación produce el reforzamiento de la Federación que amplía sus poderes, como consecuencia del paso de un Estado liberal, a un Estado democrático y social, que debe actuar en una realidad social más diversa. Asimismo, se da una ampliación de su actividad internacional como consecuencia de la globalización. En definitiva, se produce un vaciamiento de la cláusula residual ${ }^{20}$.

Con respecto al reparto de competencias, cabe señalar que se distinguen distintos tipos ${ }^{21}$. Existen competencias exclusivas del Estado federal, como la intervención federal (art. 6 CA), la declaración del estado de sitio (art. 23), las relaciones internacionales (art. 99, inc. 11 CA), o dictar los códigos de fondo y de derecho común (art. 75, inc. $12 \mathrm{CA}$ ). Estas competencias fueron delegadas por las provincias al Gobierno federal. Cabe señalar que estas atribuciones aparecen fundamentalmente en el artículo $75 \mathrm{CA}$, que enumera las atribuciones del Congreso de la Nación, el artículo 99 CA, que se refiere a las atribuciones del Poder Ejecutivo, y los artículos 116 y 117 CA que se refieren a la competencia de la Corte Suprema y los tribunales inferiores. Paralelamente, los artículos 126 y 127 CA se refieren a las competencias que están prohibidas a las provincias ${ }^{22}$.

${ }^{18}$ CSJN. «Provincia de Buenos Aires c/ Empresa Nacional de Telecomunicaciones», 24/8/1982, Fallos: 304:1186.

${ }^{19}$ CSJN. «Disco SA c/ Gobierno de la Provincia de Mendoza s/ APA», 29/8/1989, Fallos: 312:1437.

${ }^{20}$ ARAGÓN REYES, Manuel. "Problemas del Estado autonómico», Asamblea, Revista parlamentaria de la Comunidad de Madrid, $\mathrm{N}^{\circ}$ 31, 2014, pág. 27.

${ }^{21} \mathrm{Al}$ respecto, ver BIDART CAMPOS, German J. Manual..., cit., t. I, pág. 441.

${ }^{22}$ En efecto, el artículo $126 \mathrm{CA}$ establece que las provincias «no ejercen el poder delegado a la Nación. No pueden celebrar tratados parciales de carácter político; ni expedir leyes sobre comercio, o navegación interior o exterior; ni establecer aduanas provinciales; ni acuñar moneda; ni establecer bancos con facultad de emitir billetes, sin autorización del Congreso Federal; ni dictar los Códigos Civil, Comercial, Penal y de Minería, después que el Congreso los haya sancionado; ni dictar especialmente leyes sobre ciudadanía y naturalización, bancarrotas, falsificación de moneda o documentos del Estado; ni establecer derechos de tonelaje; ni armar buques de guerra o levantar ejércitos, salvo el caso de invasión exterior o de un peligro tan inminente que no admita dilación dando luego cuenta al Gobierno federal; ni nombrar o recibir 
Entre los poderes delegados por las provincias al gobierno federal cabe destacar la denominada "cláusula comercial», expresión que sintetiza la arraigada «doctrina de la corriente del comercio», originariamente concebida en los Estados Unidos por el juez Marshall en el caso «Gibbons vs. Ogden» de $1824^{23}$. Aquella noción fue receptada por la Corte Suprema argentina en sus decisiones más tempranas y de un modo constante. Esta concepción del comercio procura evitar que las actividades económicas interjurisdiccionales puedan ser entorpecidas, complicadas o impedidas por los estados provinciales, lo cual conspiraría contra la unidad del sistema federal y su regular funcionamiento ${ }^{24}$.

Existen también competencias exclusivas de las provincias, como dictar su propia Constitución, establecer impuestos directos, dictar sus leyes procesales, asegurar su régimen municipal y educación primaria, entre otras. Estas competencias se derivan de la reserva del artículo $121 \mathrm{CA}$, y de la autonomía consagrada por los artículos 122 y $123 \mathrm{CA}$, sumado al artículo $124 \mathrm{CA}$ incorporado en la reforma constitucional de $1994^{25}$.

Cabe distinguir también las competencias concurrentes, que pertenecen en común al Estado federal y a las provincias. Al respecto, puede mencionarse los impuesto indirectos internos establecido en el artículo 75, inc. 2; el artículo 75, inc. $17 \mathrm{CA}$, referido a los pueblos indígenas; el artículo 41 sobre el derecho a un medio ambiente sano, en el cual se señala que corresponde a la Nación «dictar las normas

agentes extranjeros». Por su parte, el artículo 127 CA indica que ninguna provincia "puede declarar, ni hacer la guerra a otra provincia. Sus quejas deben ser sometidas a la Corte Suprema de Justicia y dirimidas por ella. Sus hostilidades de hecho son actos de guerra civil, calificados de sedición o asonada, que el Gobierno federal debe sofocar y reprimir conforme a la ley».

2322 U. S. 1.

${ }^{24}$ CSJN. «Molinos Río de la Plata S. A c/ Provincia de Buenos Aires s/ Acción declarativa», 10/2/2009, Fallos: 332:66. Sobre la evolución del concepto de cláusula comercial en los Estados Unidos, ver CHEMERINSKY, Erwin, Constitutional law..., cit., págs. 247-279.

${ }^{25}$ El artículo 124 mencionado señala que las provincias «podrán crear regiones para el desarrollo económico y social y establecer órganos con facultades para el cumplimiento de sus fines y podrán también celebrar convenios internacionales en tanto no sean incompatibles con la política exterior de la Nación y no afecten las facultades delegadas al Gobierno federal o el crédito público de la Nación; con conocimiento del Congreso Nacional. La ciudad de Buenos Aires tendrá el régimen que se establezca a tal efecto. Corresponde a las provincias el dominio originario de los recursos naturales existentes en su territorio». Al respecto, ver CARNOTA, Walter F. «Las provincias y las relaciones internacionales: una reafirmación del federalismo (A propósito del nuevo artículo 124 de la CN)», Microjuris, Doctrina, MJDOC-338-AR, 1997. 
que contengan los presupuestos mínimos de protección, y a las provincias, las necesarias para complementarlas, sin que aquéllas alteren las jurisdicciones locales»; y la cláusula del progreso del artículo 75, inc. $18^{26}$, concordada con el artículo $125^{27}$.

Existen también las competencias compartidas entre el Estado federal y las provincias, como por ejemplo la establecida en el artículo $13 \mathrm{CA}$, relativo a la creación de nuevas provincias.

Finalmente, cabe referir que hay competencias excepcionales tanto del Estado federal como de las provincias. Respecto del primer caso, puede citarse como ejemplo la atribución del Congreso para establecer impuestos directos cuando la defensa, la seguridad común y el bien general lo exijan, y por un tiempo determinado, establecido en el artículo 75, inc. 2CA. Respecto de las competencias excepcionales de las provincias cabe citar el establecido en el artículo $126 \mathrm{CA}$, en tanto las provincias podrían dictar códigos de fondo o de derecho común hasta tanto los dicte el Congreso nacional.

Sin embargo, SAGÜES destaca que el mapa delimitatorio entre las competencias federales y provinciales es fluctuante, señalando que el derecho consuetudinario constitucional ha modificado las cuotas de poder del Gobierno federal y de las provincias generalmente a favor del primero ${ }^{28}$.

Asimismo, se ha señalado que la estructura constitucional de la federación Argentina presenta los rasgos fundamentales de todos los

${ }^{26}$ El mencionado inciso señala que le corresponde al Congreso «proveer lo conducente a la prosperidad del país, al adelanto y bienestar de todas las provincias, y al progreso de la ilustración, dictando planes de instrucción general y universitaria, y promoviendo la industria, la inmigración, la construcción de ferrocarriles y canales navegables, la colonización de tierras de propiedad nacional, la introducción y establecimiento de nuevas industrias, la importación de capitales extranjeros y la exploración de los ríos interiores, por leyes protectoras de estos fines y por concesiones temporales de privilegios y recompensas de estímulo».

${ }^{27} \mathrm{El}$ mencionado artículo dispone que las provincias pueden «celebrar tratados parciales para fines de administración de justicia, de intereses económicos y trabajos de utilidad común, con conocimiento del Congreso Federal; y promover su industria, la inmigración, la construcción de ferrocarriles y canales navegables, la colonización de tierras de propiedad provincial, la introducción y establecimiento de nuevas industrias, la importación de capitales extranjeros y la exploración de sus ríos, por leyes protectoras de estos fines, y con sus recursos propios.

Las provincias y la ciudad de Buenos Aires pueden conservar organismos de seguridad social para los empleados públicos y los profesionales; y promover el progreso económico, el desarrollo humano, la generación de empleo, la educación, la ciencia, el conocimiento y la cultura».

${ }^{28}$ SAGÜES, Néstor P. Manual de Derecho Constitucional, Astrea, Ciudad de Buenos Aires, 2007, pág. 476. 
Estados federales, las cuales son de subordinación, de participación o colaboración, y de coordinación. Las relaciones de subordinación están previstas en los artículos 5, 31 y $128 \mathrm{CA}$, que se refiere a que el orden jurídico federal tiene prelación respecto de los órdenes jurídicos provinciales. Las relaciones de participación hacen alusión a que las provincias tienen el derecho a la participación de la voluntad federal mediante su presencia igualitaria en el Senado. Finalmente, las relaciones de coordinación hacen alusión a la distribución de las competencias que corresponden al Gobierno Federal y cuales a los gobiernos locales ${ }^{29}$.

Otro de los aspectos a ser resaltados es la supremacía del derecho federal sobre el provincial (art. $31 \mathrm{CA}$ ). A su vez, dentro del derecho federal cabe desglosar al «derecho común» (art. 75, inc. $12 \mathrm{CA}$ ), como el Derecho Civil, que si bien es federal en cuanto emana del gobierno federal, y prevalece sobre el derecho provincial, no es «federal» para los fines de su "aplicación» por los tribunales provinciales, ni para su «interpretación» por la Corte mediante recurso extraordinario. En efecto, la Corte Suprema en un precedente sostuvo, por ejemplo, que determinar qué bienes del deudor se hallan sujetos al poder de agresión patrimonial del acreedor es materia de la legislación común y, como tal, prerrogativa única del Congreso Nacional, lo cual impone concluir que no corresponde a las provincias incursionar en tal ámbito, delegado al sancionarse la Ley Suprema ${ }^{30}$.

En lo que respecta a la representación de las provincias en el Poder Legislativo, cabe señalar que es igualitario para todas las provincias. En efecto, la CA dispone que el Senado se compone de tres Senadores por cada provincia y tres por la Ciudad de Buenos Aires, elegidos en forma directa y conjunta, correspondiendo dos bancas al partido político que obtenga el mayor número de votos, y la restante al partido político que le siga en número de votos (art. $54 \mathrm{CA}$ ). Asimismo, cabe destacar que los proyectos de ley, a diferencia del ordenamiento español, requieren que sean aprobados por las dos cámaras del Congreso. A su vez, el Senado tiene un importante papel en prestar su acuerdo para la designación de diversos cargos, como por ejemplo, los magistrados de la Corte Suprema. Sobre el particular, recientemente el máximo tribunal ha señalado que «resulta indudable que la participación del Senado ha sido enfáticamente reclamada por nuestros constituyentes» quienes sostuvieron que «todas las Constitu-

\footnotetext{
${ }^{29} \mathrm{Al}$ respecto, ver EKMEKDJIAN, Miguel A. Manual de la Constitución Argentina, $5^{\circ}$ ed., Depalma, Buenos Aires, 2002, págs. 341-343.

${ }^{30}$ CSJN. «Banco de la Nación Argentina c/ Martín, Miguel Ángel y otra s/ ejecución hipotecaria», 27/5/2004, Fallos: 327:1484.
} 
ciones, y muy especialmente las federales, han buscado un correctivo a la facultad peligrosa y corruptora depositada en manos de un solo hombre, de distribuir empleos honoríficos y lucrativos de un orden elevado ${ }^{31}$. Sin perjuicio de lo señalado, sabe destacar que la recientemente se ha puesto en tela de juicio la vocación federal en el comportamiento del Senado argentino ${ }^{32}$.

Por otro lado, en lo que se refiere a la cuestión de financiamiento $^{33}$, cabe señalar que la percepción de los impuestos directos corresponden primigeniamente a las provincias en virtud del artículo 121, mientras que al Estado federal solo le corresponde excepcionalmente y por tiempo limitado. En cuanto a los impuestos indirectos externos le corresponden al Estado federal exclusivamente (arts. 4 y 75, inc. 11 CA) y nunca a las provincias (arts. 4, 9 y 126 CA). Los impuestos indirectos internos con concurrentes del Estado federal y las provincias (art. 4 y art. 75 , inc. $2 \mathrm{CA})^{34}$.

En este contexto, cabe señalar que el artículo 75, inc. 2 CA determina que una ley convenio, sobre la base de acuerdos entre la Nación y las provincias, debe instituir regímenes de coparticipación de estas contribuciones, garantizando la automaticidad en la remisión de los fondos. A su vez, indica que la distribución entre la Nación, las provincias y la ciudad de Buenos Aires y entre éstas, se efectuará en relación directa a las competencias, servicios y funciones de cada una de ellas, y debe contemplar criterios objetivos de reparto: «será equitativa, solidaria y dará prioridad al logro de un grado equivalente de desarrollo, calidad de vida e igualdad de oportunidades en todo el terri-

${ }^{31}$ CSJN. «Aparicio, Ana Beatriz y otros c/ EN -CSJN- Consejo de la Magistratura - artículo 110 s/ empleo público», 21/4/2015, Fallo CSJ 1095/2008 (44-A).

${ }^{32}$ CERRO, María Marta. "La ausencia de vocación federal en el comportamiento del Senado argentino", Cuadernos Manuel Giménez Abad, N. . 9, 2015, págs. 159168. En el trabajo se analiza el focus de la representación territorial, desde dos dimensiones: por un lado, la «actitudinal», que mide el grado de importancia que otorgan los senadores a los territorios en sus concepciones representativas y, por el otro, de comportamiento, que mide el caudal de proyectos de ley que estos inician y que afectan solo a sus territorios, es decir, que tienen beneficios geográficamente concentrados.

${ }_{33}$ De modo general, puede consultarse las obras de ASENSIO, Miguel Ángel, $\mathrm{Fe}$ deralismo fiscal: fundamentos. Análisis comparado y el caso argentino, Ciudad Argentina, Buenos Aires, 2002; PORTO, Alberto, dir., Disparidades regionales y Federalismo fiscal, Universidad Nacional de La Plata, La Plata, 2004; y GARAT, Pablo M. «La coordinación financiera y el sistema de coparticipación federal a partir de la reforma constitucional de 1994», Microjuris, Doctrina, MJ-DOC-900-AR, 1999.

${ }^{34}$ Conf. EKMEKDJIAN, Miguel A. Manual..., cit., págs. 379-402. Asimismo, sobre el ejercicio concurrente de la potestad tributaria entre la Nación y las provincias, ver SPISSO, Rodolfo R. "Fortalecimiento del federalismo. Un mandato incumplido», Revista Jurídica Argentina La Ley, t. 2015-A, pág. 740. 
torio nacional». Sin embargo, cabe señalar que la todavía no ha sido sancionada la ley convenio mencionada. Asimismo, se ha dicho que resulta necesario que la masa coparticipable se restablezca de acuerdo a los criterios emanados de la Constitución, para lo cual es menester derogar o modificar ostensiblemente la casi totalidad de asignaciones específicas vigentes, que la han disminuido, consolidando el actual unitarismo fiscal ${ }^{35}$.

Finalmente, cabe reseñar que el artículo 6 CA prevé las causales de intervención federal, señalando que el Gobierno Federal interviene en el territorio de las provincias «para garantir la forma republicana de gobierno, o repeler invasiones exteriores, y a requisición de sus autoridades constituidas para sostenerlas o restablecerlas, si hubiesen sido depuestas por la sedición, o por invasión de otra provincia» ${ }^{36}$.

Sin perjuicio de todo lo expuesto, cabe señalar que la doctrina ha puesto de relieve que si bien la Constitución estableció una forma federal de Estado, ello no impidió un proceso de centralización del país en torno al área metropolitana de Buenos Aires y a un predominio del Gobierno nacional ${ }^{37}$. En efecto, recientemente se han expuesto las violaciones constitucionales relacionadas con el proyecto federal de la Constitución Argentina. A saber:

a) todavía no se sancionó la ley convenio de coparticipación impositiva ni se reglamentó el organismo fiscal federal con los criterios fijados en el artículo 75 inc. 2 de la Constitución Nacional, que conforme a la cláusula transitoria sexta de la Ley Suprema debían estar establecidos a fines del año 1996; b) siguen dictándose leyes de presupuesto que no se adecuan a los mandatos del artículo 75 inc. 8 de la Constitución Nacional en cuanto a los principios federales para el gasto público, c) el Congreso prorrogó la legislación de emergencia y mantiene la delegación de funciones en el Poder Ejecutivo, lo cual también lesiona el federalismo y centraliza el país, mediante el gobierno por decreto; d) continúa una notoria insuficiencia en el avance del proceso de integración regional dentro del país, o peor aún, se ha detenido casi por completo; e) no se cumplen otras nor-

${ }^{35}$ HERNÁNDEZ, Antonio María. «Veinte propuestas para fortalecer el federalismo argentino", Revista Jurídica Argentina La Ley, t. 2014-D, pág. 847. Sobre las perspectivas del sistema, ver también GARAT, Pablo M. «La distribución de la renta tributaria federal en la organización constitucional argentina y el futuro del régimen de coparticipación», Microjuris, Doctrina, MJ-DOC-5670-AR, 2012.

${ }^{36}$ Sobre el particular, ver SOLA, Juan V. Derecho Constitucional, Lexis-Nexis, Buenos Aires, 2006.

${ }^{37}$ HERNÁNDEZ, Antonio María. «Presidencialismo y federalismo en argentina», en HÄBERLE, Peter; GARCÍA BELAUNDE, Domingo (coords.), El control del poder. Homenaje a Diego Valadés, Universidad Nacional Autónoma de México, México, 2011, t. II, págs. 37-73. 
mas referidas a los aspectos económicos del federalismo, f) persisten leyes centralistas como las de Financiamiento Educativo y Nacional de Educación, que también lesionan el federalismo y las atribuciones de las provincias (...) que es necesario modificar o derogar, y g) no existe una autonomía plena para la Ciudad Autónoma de Buenos Aires $^{38}$.

Se ha dicho entonces que esta situación conlleva -junto con las afectaciones al sistema republicano- una profunda decadencia del Estado constitucional y democrático de derecho. Se advirtió también que continúa la grave patología institucional del «hiperpresidencialismo», que impide la vigencia de la república federal, que fuera el objetivo perseguido por los padres fundadores de la nacionalidad. Finalmente, se ha puesto de resalto la inadecuada ordenación territorial argentina -cuyo eje central es la superpoblación de la provincia de Buenos Aires-y las obsoletas comunicaciones terrestres, que acrecientan el aislamiento de las provincias, y exigen soluciones impostergables $^{39}$.

En relación a estas problemáticas planteadas, se han planteado diversas propuestas a efectos de fortalecer el federalismo argentino, tales como adoptar medidas para que se cumplan los principios del sistema republicano y federal de la Constitución Nacional; poner fin con el hiperpresidencialismo; fortalecer el rol federal del Congreso y del Senado de la Nación, en particular; reafirmar el rol de la Corte Suprema de Justicia de la Nación como garante del federalismo; promover un nuevo ordenamiento territorial del país que modifique la enorme concentración de poder político, económico, demográfico y cultural en el área metropolitana de Buenos Aires; sancionar la ley convenio de coparticipación impositiva, de conformidad a los principios constitucionales; respetar los principios federales en la sanción anual de los presupuestos; federalizar el Banco Central; afianzar el federalismo de coordinación o concertación mediante un mejor ejercicio de relaciones interjurisdiccionales y la creación de una Asociación o Conferencia Nacional de Gobernadores; realizar una planificación federal para el desarrollo del país, con participación de los distintos niveles estaduales; promover las regiones para el desarrollo económico y social; impulsar el nuevo rol de regiones, provincias y municipios en los procesos de integración nacional y supranacional; fortalecer las autonomías provinciales, de la Ciudad Autónoma de

${ }^{38}$ HERNANDEZ, Antonio María. «Informe sobre el federalismo argentino año 2013-», Cuadernos de Federalismo, N. ${ }^{\circ}$ XXVII, Instituto de Federalismo, Academia Nacional de Derecho y Ciencias Sociales de Córdoba, Córdoba, 2014, pág. 15.

${ }^{39}$ HERNANDEZ, Antonio María. «Informe...», cit., pág. 16. 
Buenos Aires y de los municipios; modificar o derogar la legislación centralista vigente y las políticas respectivas: federalizar la educación; ejercer un federalismo de concertación para la exploración, explotación y aprovechamiento de los recursos naturales; federalizar los servicios públicos de competencia nacional; afianzar los principios federales en la doctrina y organización de los partidos políticos; y, finalmente, trasladar la Capital ${ }^{40}$.

\section{EL SISTEMA AUTONÓMICO ESPAÑOL}

Habiendo efectuado un paneo muy breve respecto del sistema federal argentino, corresponde adentrarnos en el sistema autonómico español, el cual es visto por algunos autores como un sistema federal. Por ejemplo, WATTS señala que si bien España no ha adoptado el título de "federación», en la práctica muestra las instituciones y los procesos normalmente característicos de las federaciones ${ }^{41}$. Si bien existen muchas coincidencias con los sistemas federales, a continuación se va a analizar el sistema autonómico español mostrándose algunas diferencias.

Se ha dicho que España es un país de países, o una nación de naciones, aunque se afirma que a pesar de ser el estado más antiguo de la Europa moderna, sólo desarrolló la centralización de las políticas de construcción de la nación en la época contemporánea ${ }^{42}$.

En efecto, luego de la dictadura franquista, las medidas adoptadas durante la transición política pusieron en marcha el modelo territorial del estado español y marcaron profundamente su desarrollo. Contrariamente al franquismo, que implicaba dictadura y centralización, en la etapa de la transición se creía que el nuevo régimen político tendría que ser democracia y descentralización ${ }^{43}$.

${ }^{40}$ Excedería el propósito de este trabajo desarrollar cada una de estas propuestas. Sobre el particular, ver HERNÁNDEZ, Antonio María. «Veinte propuestas...», cit.; y HERNANDEZ, Antonio María; REZK Ernesto; CAPELLO, Marcelo, coords. Propuestas para fortalecer el federalismo argentino, Academia Nacional de Derecho y Ciencias Sociales de Córdoba, Córdoba, 2015.

${ }^{41}$ WATTS, Ronald L. "Comparative...», cit., pág. 330. Ver también, ZAPATA BARRERO, Ricard. "Spain», en JOPPKE, Christian; LESLIE SEIDLE, F. (dir.), Immigrant Integration in Federal Countries, McGill-Queen's University Press, Montréal y Kingston, 2012, págs. 135-160.

${ }_{42}$ MORENO, Luis. "Federal democracy in plural Spain», en BURGESS, Michael; GAGNON, Alain G. (eds.), Federal..., cit., págs. 160-177.

${ }^{43}$ ARAGÓN REYES, Manuel. Estudios de Derecho Constitucional, $3^{\circ}$ ed., Centro de Estudios Políticos y Constitucionales, Madrid, 2013, pág. 825. 
Sin embargo, la propia Constitución trasladó a un momento posterior la concreción y el desarrollo de la autonomía territorial, cuando se establecieran los Estatutos de Autonomía. En efecto, la Constitución Española de 1978 no determinó un modelo específico de Estado desde el punto de vista de la organización territorial, sino que solo previó un modelo genérico, es decir, un Estado con autonomías territoriales, estableciendo un marco territorial y unos principios básicos sobre la materia que habrían de ser observados a la hora de concretar, mediante el desarrollo autonómico, la forma territorial resultante, cualquiera que fuera ésta ${ }^{44}$.

En este mismo sentido, se ha dicho que a diferencia de lo que haría una Constitución de un Estado federal, la Constitución española ni crea ella misma a los entes territoriales llamadas Comunidades Autónomas, ni las dota de potestades o competencias. Por el contrario, esa tarea la difiere a ciertas normas del sistema estatal estos son los Estatutos de Autonomía y las leyes previstas por el artículo $150 \mathrm{CE}$ - las que tienen una función «estatuyente», esto es, constitución de la autonomía misma y de paralela delimitación de sus poderes, incluidos los normativos ${ }^{45}$. La doctrina se refiere así al "carácter dispositivo» de la autonomía territorial de la $\mathrm{CE}$, la cual no diseña un mapa autonómico, es decir, la división del territorio nacional en un número determinados de Comunidades Autónomas, ni el contenido concreto de la Autonomía, el cual debe ser asumido dentro del cuadro ofrecido por la Constitución a través del respectivo Estatuto ${ }^{46}$.

En este contexto, cabe señalar que en el Preámbulo de la Constitución Española se resalta la voluntad de la Nación española de «[p]roteger a todos los españoles y pueblos de España en el ejercicio de los derechos humanos, sus culturas y tradiciones, lenguas e instituciones». En su artículo 2 se refiera a la unidad de la Nación española, a la vez que reconoce la autonomía territorial: «La Constitución se fundamenta en la indisoluble unidad de la Nación española, patria común e indivisible de todos los españoles, y reconoce y garantiza el derecho a la autonomía de las nacionalidades y regiones que la integran y la solidaridad entre todas ellas». Asimismo, el artículo 3.1 CE si bien señala que el castellano es la lengua española oficial del Esta-

${ }^{44}$ ARAGÓN REYES, Manuel. Estudios..., cit., págs. 826-827.

${ }^{45}$ GARRORENA MORALES, Ángel. Derecho Constitucional. Teoría de la Constitución y sistema de fuentes, $3^{\circ}$ ed., Centro de Estudios Políticos y Constitucionales, Madrid, 2014, págs. 221-222.

${ }^{46}$ GARCÍA DE ENTERRÍA, Eduardo; RAMÓN FERNANDEZ, Tomás. Curso de derecho administrativo, $16^{\circ}$ ed., Civitas, Navarra, 2013, pág. 320. 
do, en su apartado 2 reconoce que las demás lenguas españolas serán también oficiales en las respectivas Comunidades Autónomas de acuerdo con sus Estatutos.

La Constitución Española dedica su título VIII a la organización territorial del Estado, del que se ha señalado que sólo puede ser entendido cabalmente en clave histórica ${ }^{47}$. El titulo está compuesto de tres capítulos. El primero de ellos dedicado a los principios generales, el segundo a la administración local y el tercero a las Comunidades Autónomas.

En cuanto a la organización territorial, el artículo $137 \mathrm{CE}$ señala que el Estado se organiza en municipios, en provincias y en las Comunidades Autónomas que se constituyan, gozando todas estas entidades de autonomía para la gestión de sus respectivos intereses. Asimismo, cabe señalar que la acción de las Comunidades Autónomas se rigen por varios principios, como los de la solidaridad (arts. 2 y 138.1 $\mathrm{CE})^{48}$, la igualdad de las Comunidades Autónomas (138.2 CE), la igualdad de derechos y obligaciones de los ciudadanos (art. 139.1 CE) y de unidad económica (139.2 CE $)^{49}$.

Desde un comienzo, el TC ha señalado que la Constitución parte de la unidad de la Nación española que se constituye en Estado social y democrático de Derecho, cuyos poderes emanan del pueblo español en el que reside la soberanía nacional. Esta unidad se traduce así en una organización -el Estado- para todo el territorio nacional. Pero los órganos generales del Estado no ejercen la totalidad del poder público, porque la Constitución prevé, con arreglo a una distribución vertical de poderes, la participación en el ejercicio del poder de entidades territoriales de distinto rango, tal como se expresa en el artículo $137 \mathrm{CE}$. El TC destaca, pues, que la norma señalada refleja una concepción amplia y compleja del Estado, compuesto por una pluralidad de organizaciones de carácter territorial dotadas de autonomía. Sobre este concepto, el TC ha destacado que «hace referencia a un poder limitado. En efecto, autonomía no es soberanía -y aún este po-

${ }^{47}$ En efecto, en relación a las raíces históricas de la normativa constitucional, ver SANTAMARÍA PASTOR, Juan Alfonso, Fundamentos de Derecho Administrativo, Centro de Estudios Ramón Areces, Madrid, 1991, págs. 1070-1074.

${ }^{48}$ Respecto a este principio, el TC se ha referido en la STC 64/1990, de 5 de abril, FJ 7, que debe existir un «deber de auxilio recíproco» (STC 18/1982, de 4 de mayo, FJ 4), de «recíproco apoyo y mutua lealtad» (STC 96/1986, de 10 de julio, FJ 3), y «concreción, a su vez, del más amplio deber de fidelidad a la Constitución» (STC 11/1986, de 28 de enero, FJ 5).

${ }^{49}$ Ver al respecto, PÉREZ TREMPS, Pablo. «Principios generales de la organización territorial del Estado», en Derecho Constitucional, $7^{\circ}$ ed., Tirant lo blanch, Valencia, 2007, págs. 311-315. 
der tiene sus límites-, y dado que cada organización territorial dotada de autonomía es una parte del todo, en ningún caso el principio de autonomía puede oponerse al de unidad, sino que es precisamente dentro de éste donde alcanza su verdadero sentido, como expresa el artículo 2 de la Constitución» ${ }^{50}$.

Sobre el marco establecido por la Constitución, cabe señalar que la norma fundamental previó que el acceso a la autonomía sería voluntario (arts. 143 y $151 \mathrm{CE}$ ). De este modo, el artículo 143.1 CE dispone que «... las provincias limítrofes con características históricas, culturales y económicas comunes, los territorios insulares y las provincias con entidad regional histórica podrán acceder a su autogobierno y constituirse en Comunidades Autónomas...». Sin embargo, la Constitución reconoce dos grados de autonomía: una autonomía de primer grado, con el máximo de las competencias (art. 151.1 CE), y una autonomía de segundo grado, con menos competencias (arts. 143 y 148.1). Sin embargo, estas diferencias podían ser sólo transitorias, ya que transcurridos cinco años (art. 148.2), las Comunidades Autónomas de segundo grado podrían ampliar sus competencias igualándose a las primeras ${ }^{51}$. Asimismo, cabe indicar que el procedimiento de aprobación y reforma de los Estatutos de Autonomía de cada una de las Comunidades de una y otra categoría son diversos, incluyéndose por ejemplo en las comunidades de primera categoría un referéndum del cuerpo electoral (art. 151.2).

En este contexto, se ha dicho que la diferencia más importante entre los Estatutos y las Constituciones de los Estados federados estriba en la forma de su elaboración y aprobación, la cual en los federalismos depende sólo de las instituciones de cada Estado ${ }^{52}$.

Se puede hablar de tres fases del desarrollo autonómico ${ }^{53}$. En la primera fase, de 1979 a 1983, se dio una generalización diferenciada de la autonomía política en todo el territorio. Hubo cinco Comunidades con el mayor nivel competencial. Por un lado, País Vasco, Cataluña y Galicia, en virtud de la disposición transitoria segunda de la Constitución; Navarra, en virtud de la disposición adicional primera de la Constitución, por la cual se dictó la Ley Orgánica de Reintegración y Amejoramiento del Régimen Foral de Navarra, de 10 de agosto de 1982, que opera como un Estatuto de Autono-

\footnotetext{
${ }^{50}$ STC 4/1981, de 2 de febrero, FJ 3.

${ }^{51}$ ARAGÓN REYES. Manuel, Estudios..., cit., pág. 828.

${ }^{52}$ AJA, Eliseo. Estado autonómico y reforma federal, Alianza, Madrid, 2014, pág. 117.

${ }^{53}$ Ver al respecto, ARAGÓN REYES. Manuel, Estudios..., cit., págs. 829-833; y AJA, Eliseo. Estado..., cit., págs. 31-111.
} 
mía ${ }^{54}$; y Andalucía, por haber escogido un mayor grado de autonomía. Otras dos Comunidades tuvieron competencias cuasi-plenas, Valencia y las Islas Canarias, en virtud de respectivas leyes orgánicas de transferencias. El resto de las Comunidades tenían un menor grado de competencias.

La segunda fase, se dio a partir de 1992 cuando se produjo una cierta homogeneización de la autonomía. En virtud de los acuerdos autonómicos de 1992, se dictó la Ley Orgánica 9/1992, de 23 de diciembre, mediante el cual se realizó una transferencia generalizada de competencias, procediéndose luego a la reforma de los Estatutos de las diversas Comunidades Autónomas. Asimismo se completó el «mapa autonómico» a todo el territorio al dictarse los Estatutos de Autonomía de las ciudades de Ceuta y Melilla, aunque estás poseen una autonomía meramente administrativa y no política.

La tercera fase se dio a inicios del siglo XXI, con la reforma de varios Estatutos de Autonomía, de los que cabe destacar el de la Comunidad Valenciana, del cual el TC se pronunció en la sentencia 247/2007, de 12 de diciembre, y el de Cataluña, el cual el TC se pronunció en la sentencia 31/2010, de 28 de junio, a la que se hará referencia más adelante.

En definitiva, cabe señalar que la Constitución es la «norma de habilitación» sobre la que un determinado territorio sustenta su derecho a acceder a la autonomía y a dotarse de los correspondientes poderes de autogobierno, si lo desea, y el Estatuto es la efectiva «norma de acceso» a esa autonomía y de constitución de tales poderes, por lo que sólo a ella cabe atribuir con eficacia inmediata, el resultado de su existencia a derecho y, por consiguiente, su legitimidad ${ }^{55}$.

Por otro lado, si bien excedería el propósito de este trabajo analizar en detalle el sistema de distribución competencial en el sistema español, cabe hacer una breve referencia al respecto, diferenciándolo de los sistemas federales ${ }^{56}$. En efecto, en estos últimos, la división competencial está netamente definida en la Constitución. Además, a diferencia de los Estados federales clásicos, en España la función de administrar justicia es una competencia exclusiva del

${ }^{54}$ SSTC 16/1984, de 6 de febrero, y 15/2000, de 20 de enero.

55 GARRORENA MORALES, Ángel. Derecho..., cit., pág. 222.

${ }^{56}$ Por otro lado, es clara la incidencia en el sistema de distribución de competencias de la pertenencia de España a la Unión Europea. Al respecto, ver FERNÁNDEZ FARRERES, Germán. La contribución del Tribunal Constitucional al Estado autonómico, Iustel, Madrid, 2005, págs. 463 y ss. 
Estado central (art. 149.1.5 CE), y no de las Comunidades Autónomas.

Asimismo, si bien la Constitución reconoce que es competencia del Estado legislar en materia civil, a la vez admite la «conservación, modificación y desarrollo por las Comunidades Autónomas de los derechos civiles, forales o especiales, allí donde existan» (art. 149.1.8 CE), cuestión que se diferencia del sistema federal argentino.

El TC desde sus inicios ha señalado que para determinar si una materia es de la competencia del Estado o de la Comunidad Autónoma, o si existe un régimen de concurrencia, «resulta en principio decisorio, el texto del Estatuto de Autonomía de la Comunidad Autónoma, a través del cual, se produce la asunción de competencias. Si el examen del Estatuto correspondiente revela que la materia de que se trate no está incluida en el mismo, no cabe duda que la competencia será estatal, pues así lo dice expresamente el artículo 149.3 de la Constitución». En efecto, la mencionada disposición establece que "[l]as materias no atribuidas expresamente al Estado por esta Constitución podrán corresponder a las Comunidades Autónomas, en virtud de sus respectivos Estatutos. La competencia sobre las materias que no se hayan asumido por los Estatutos de Autonomía corresponderá al Estado...». Sin perjuicio de lo expuesto, el TC al mismo tiempo afirma que los Estatutos deben ser siempre interpretados de conformidad con la Constitución ${ }^{57}$.

Asimismo, cabe resaltar que en la doctrina se ha puesto especial relieve en las competencias del Estado llamadas «horizontales», por ejemplo, cuando la Constitución le reserva al Estado «las bases y la coordinación de la planificación general de la actividad económica» (art. 149.1.13 CE), siendo esta una atribución amplísima de competencias, por lo que es difícil encontrar ámbitos que no tengan o no puedan tener relevancia económica ${ }^{58}$.

Sobre la cuestión competencial, cabe resaltar, por último, que si bien los Estatutos de Autonomía son la norma a la que fundamentalmente confía la Constitución la distribución de competencias entre la Comunidad Autónoma y el Estado, el artículo 150 CE prevé tres mecanismos que permiten reajustar excepcionalmente esa distribución, que ha quedado plasmada en tres tipos de leyes: las leyes marco, las

${ }^{57}$ STC 18/1982, de 4 de mayo, FJ 1.

${ }^{58} \mathrm{Al}$ respecto, puede verse LÓPEZ GUERRA, Luis. «La distribución de competencias entre el Estado y las Comunidades Autónomas», en LÓPEZ GUERRA, Luis y otros. Derecho..., cit., págs. 339-340. 
leyes orgánicas de transferencias y las leyes de armonización. Las dos primeras se dirigen a ampliar las competencias de las Comunidades Autónomas, mientras que el tercer tipo se orienta a restringir o más bien a disciplinar tales competencias ${ }^{59}$.

En lo que respecta a la representación de las comunidades en las Cortes Generales, si bien el artículo 69.1 CE señala que el Senado es la Cámara de representación territorial, lo cierto es que no existe una representación igualitaria entre todos los territorios. En cuanto a su composición, cabe señalar que la CE establece, entre otras cuestiones, que en cada provincia se elegirán cuatro Senadores, y que las Comunidades Autónomas designarán además un senador y otro más por cada millón de habitantes de su respectivo territorio (art. 69.2 y 69.5 CE). Asimismo, cabe señalar que conforme surge del artículo $90 \mathrm{CE}$, si bien el Senado puede oponer su veto o introducir enmiendas a un proyecto aprobado por el Congreso de los Diputados, es la voluntad de este último la que en definitiva prevalece. Es por ello que el TC ha señalado que el sistema parlamentario español se caracteriza por un «notorio bicameralismo imperfecto ${ }^{60}$.

En lo que respecta al financiamiento de las Comunidades Autónomas, la CE lo regula en los artículos 156 a 158, normas de las cuales se ha dicho que son pocas y demasiado genéricas ${ }^{61}$. El artículo 156 CE se refiere a los principios de autonomía financiera, de coordinación y de solidaridad entre todos los españoles, mientras que el artículo 157.1 CE enumera los recursos de las Comunidades Autónomas $^{62}$. Cabe destacar sobre el punto el artículo 157.3 CE que indica que mediante ley orgánica se puede regular el ejercicio de las competencias financieras, las normas para resolver los conflictos que pudieran surgir y las posibles formas de colaboración financiera entre las Comunidades Autónomas y el Estado. De este modo, se advierte que la materia de financiamiento se desconstitucionaliza, en tanto remite a una ley orgánica. En este contexto, se ha dicho que la falta de normas constitucionales, convierte a la LOFCA (Ley Orgánica de Finan-

\footnotetext{
${ }^{59}$ Ver al respecto, GARRORENA MORALES, Ángel. Derecho..., cit., págs. 229-233.

${ }^{60}$ SSTC 155/2005, de 9 de junio, FJ 9; y 237/2012, de 13 de diciembre, FJ 7.

${ }^{61}$ Confr. AJA, Eliseo. Estado..., cit., pág. 234.

${ }^{62}$ La norma señala que los recursos de las Comunidades Autónomas estarán constituidos por los impuestos cedidos total o parcialmente por el Estado, y los recargos sobre impuestos estatales y otras participaciones en los ingresos del Estado: sus propios impuestos, tasas y contribuciones especiales; las transferencias de un Fondo de Compensación interterritorial y otras asignaciones con cargo a los Presupuestos Generales del Estado; los rendimientos procedentes de su patrimonio e ingresos de derecho privado; y el producto de las operaciones de crédito.
} 
ciación de las Comunidades Autónomas) en el verdadero canon de constitucionalidad. Sin perjuicio de lo expuesto, cabe resaltar que ha habido cambios en la LOFCA cada cinco años, concretamente en los años 1987, 1992, 1997, 2002 y la última de 2009. Finalmente, cabe destacar la reducción de la autonomía financiera del gasto por la Unión Europea, y la importante incidencia de la reforma del artículo $135 \mathrm{CE}$ efectuada en 2011, incorporando el principio de estabilidad presupuestaria ${ }^{63}$.

Por otro lado, cabe señalar que el artículo $155 \mathrm{CE}$ contempla un mecanismo de control subsidiario para situaciones excepcionales o extremas, consistentes en el incumplimiento por parte de las Comunidades Autónomas de las obligaciones impuestas por la Constitución o las leyes o en actuaciones de aquellas que atenten gravemente al interés general de España. El precepto, que se inspira en la instituto de la llamada "coerción federal» (Bundeszwang), prevista en el artículo 37 de la Ley Fundamental de Bonn, y señala que en los casos antes descriptos «el Gobierno, previo requerimiento al Presidente de la Comunidad Autónoma y, en el caso de no ser atendido, con la aprobación por mayoría absoluta del Senado, podrá adoptar las medidas necesarias para obligar a aquélla al cumplimiento forzoso de dichas obligaciones o para la protección del mencionado interés general».

Para concluir este apartado, cabe destacar que ARAGÓN REYES ha señalado que en la actualidad, el modelo territorial de España, aunque con algunas imperfecciones y carencias, se encuentra bastante estructurado y definido ${ }^{64}$, si bien más recientemente ha planteado algunas propuestas de reforma ${ }^{65}$. Por su parte, AJA afirma que las Comunidades Autónomas han experimentado durante tres décadas una autonomía parecida a la federal, pero considera necesario realizar una reforma a fin de que España adopte plenamente un sistema federal, ya que cree que es la mejor forma de Estado

${ }^{63}$ Sobre la cuestión de financiamiento, el TC ha destacado que «el Estado tiene atribuida la competencia exclusiva en materia de "Hacienda general" (art. 149.1.14 $\mathrm{CE}$ ), así como la potestad originaria para establecer tributos mediante ley (art. 133.1 $\mathrm{CE}$ ), lo que, unido a que también corresponde al legislador orgánico la regulación del ejercicio de las competencias financieras de las Comunidades Autónomas, (art. 157.3 $\mathrm{CE}$ ), determina que aquél sea competente para regular no sólo sus propios tributos, sino también el marco general de todo el sistema tributario y la delimitación de las competencias financieras de las Comunidades Autónomas respecto de las del propio Estado'» (STC 31/2010, de 28 de junio, FJ 130).

${ }^{64}$ ARAGÓN REYES, Manuel. Estudios..., cit., pág. 823.

${ }^{65}$ ARAGÓN REYES, Manuel. «Problemas del Estado...», cit., págs. 13-32. 
para contener posiciones políticas diversas, incluidas las de tipo nacional ${ }^{66}$.

\section{LA NATURALEZA JURÍDICA DE LOS ESTATUTOS DE AUTONOMÍA}

\section{IV.A. Los Estatutos de Autonomía como «norma institucional básica» y como «ley orgánica»}

El artículo 147.1 de la CE define a los Estatutos de Autonomía como «la norma institucional básica de cada Comunidad Autónoma». A la vez, el artículo 81.2 CE señala que son leyes orgánicas «las que aprueban los Estatutos de Autonomía». Esto último implica que para su adopción intervenga una mayoría reforzada, la mayoría absoluta del Congreso.

Sin embargo, cabe señalar que hay notables diferencias entre los Estatutos de Autonomía y las demás leyes orgánicas. Mientras que a estas últimas el Estado puede modificarlas o derogarlas unilateralmente, los Estatutos de Autonomía tienen una particularidad en su procedimiento, en tanto no pueden ser aprobadas ni reformadas si la Comunidad Autónoma correspondiente no inicia o no consiente tal decisión. Por lo tanto, no están sujetos al arbitrio unilateral del Estado. Pero a la vez, corresponde resaltar que los Estatutos deben ser aprobados por las Cortes Generales. Por lo tanto, no podría decirse que los Estatutos de Autonomía son las Constituciones de las Comunidades Autónomas, dependientes únicamente de la sola voluntad de éstas, en tanto están caracterizados por su bilateralidad, es decir que requieren la concurrencia del Estado y de la respectiva Comunidad Autónoma. En definitiva, los Estatutos son una categoría normativa específica y singular ${ }^{67}$.

Sin perjuicio de ello, cabe resaltar que, a la vez, desde un punto de vista material, los Estatutos tienen un cometido que ni siquiera pueden realizar las constituciones de los Estados miembros de una federación, sino sólo la Constitución federal: la atribución de competencias a las entidades territoriales autónomas, aunque siempre en el marco de la Constitución ${ }^{68}$.

${ }^{66}$ AJA, Eliseo. Estado..., cit., pág. 369.

${ }^{67}$ GARRORENA MORALES, Ángel. Derecho..., cit., págs. 226-227.

${ }^{68}$ ARAGÓN REYES, Manuel. Estudios..., cit., pág. 840. 


\section{IV.B. El contenido de los Estatutos de Autonomía}

En lo que respecta al contenido de los Estatutos de Autonomía, cabe señalar, en primer lugar, que la Constitución les ha impuesto un contenido "necesario» ${ }^{69}$. Es el que impone el artículo 147.2. CE que señala que los estatutos «deberán» contener, la denominación de la Comunidad que mejor corresponda a su identidad histórica; la delimitación de su territorio; la denominación, organización y sede de las instituciones autónomas propias; y las competencias asumidas dentro del marco establecido en la Constitución y las bases para el traspaso de los servicios correspondientes a las mismas. Sobre el punto, cabe señalar que la Constitución sólo ha fijado un contenido mínimo.

En segundo lugar, existen otros contenidos que deben estar en los Estatutos, y sin embargo no están previstos en el artículo 147.2 CE antes citado. Se han descripto a estos como un «contenido adicional constitucionalmente previsto», el cual es lo relativo a la lengua propia, a las banderas o el procedimiento de designación de Senadores en representación de la Comunidad Autónoma.

En tercer lugar, también, cabe reconocer a los Estatutos de Autonomía un "contenido implícito» que es aquel que si bien no está expresamente previsto en la Constitución, es necesario para el eficaz desarrollo por parte de la Comunidad Autónoma de sus funciones.

Finalmente, se ha hecho referencia al «contenido estatutario posible». Éste se refiere, por ejemplo, a que las Comunidades Autónomas puedan incluir en sus Estatutos declaraciones de derechos. El TC ha admitido este tipo de contenido, siempre que se respeten ciertas condiciones, tales como aquellas que no afecten la integridad de las competencias estatales, y que tengan debida relación con la condición del Estatuto como «norma institucional básica». Asimismo, aclaró que los derechos que fije el Estatuto son meros derechos estatutarios y no constitucionales $^{70}$.

\section{IV.C. Los Estatutos de Autonomía como normas funcionalmente constitucionales}

En lo que respecta a la posición de los Estatutos de Autonomía dentro del ordenamiento jurídico, es claro que no son normas formal-

\footnotetext{
${ }^{69}$ Sobre el punto, ver GARRORENA MORALES, Ángel. Derecho..., cit., págs. 223-224.

${ }^{70}$ STC 247/2007, de 12 de diciembre y 31/2010, de 28 de junio. Cfr. GARRORENA MORALES, Ángel. Derecho..., cit., pág. 223-224.
} 
mente constituyentes, GARRORENA MORALES sostiene que sí son normas funcionalmente constitucionales. Al respecto, afirma que los Estatutos cumplen una doble función que es materialmente constitucional: la de constituir a cada Comunidad, y la de completar la definición constitucional del territorio del Estado. Así, afirma que a los Estatutos les corresponde una posición de superioridad que sólo debe ceder ante la supremacía de la Constitución, por lo que se habla de un «bloque de constitucionalidad» ${ }^{71}$.

En el mismo sentido, ARAGÓN REYES sostiene que la realización y determinación del modelo territorial esta en mano de los Estatutos de Autonomía que, sin ser Constitución, realiza el cometido que sólo las constituciones suelen cumplir ${ }^{72}$.

\section{IV.D. Los Estatutos de Autonomía en la STC 31/2010}

Cabe referirnos ahora específicamente a la STC 31/2010 ${ }^{73}$ que se pronunció sobre la constitucionalidad de la reforma del Estatuto de Cataluña. Si bien se hará referencia a algunas cuestiones ya abordadas, consideramos que su importancia amerita un tratamiento diferenciado ${ }^{74}$. El Estatuto catalán no se reformaba desde 1979, y pasó de 57 artículos a 223 y sus 22 cláusulas finales, siendo prácticamente un Estatuto nuevo. La STC 31/2010 generó muchos rechazos, en especial de la población de Cataluña, por considerarla política ${ }^{75}$. El TC

${ }^{71}$ GARRORENA MORALES, Ángel. Derecho..., cit., pág. 228.

${ }^{72}$ ARAGÓN REYES, Manuel. Estudios..., cit., pág. 843.

${ }^{73}$ El voto mayoritario está compuesto por los magistrados María Emilia Casas Baamonde, Guillermo Jiménez Sánchez, Elisa Pérez Vera, Pascual Sala Sánchez, y Manuel Aragón Reyes. Efectuaron sendos votos particulares los magistrados Vicente Conde Martín de Hijas, Javier Delgado Barrio, Eugeni Gay Montalvo, Jorge Rodríguez-Zapata Pérez, y Ramón Rodríguez Arribas.

${ }^{74}$ Un agudo análisis de la sentencia puede verse en REQUEJO PAGÉS, Juan Luis y otros. "Doctrina del Tribunal Constitucional durante el segundo cuatrimestre de 2010», Revista Española de Derecho Constitucional, N 90, 2010, págs. 185-243. Ver también, TUR AUSINA, Rosario; Álvarez CONDE, Enrique. Las consecuencias jurídicas de la sentencia 31/2010, de 28 de junio, del Tribunal Constitucional sobre el Estatuto de Autonomía de Cataluña. La sentencia de la perfecta libertad, Aranzadi-Thomnson Reuters, Pamplona, 2010; LÓPEZ BASAGUREN, Alberto. «Current issues around territorial autonomy in Spain», en LÓPEZ BASAGUREN, Alberto; ESCAJEDO SAN EPIFANIO, Leire (coords.), The Ways of Federalism in Western Countries and the Horizons of Territorial Autonomy in Spain, Vol. I, Springer-Verlag, Berlin - Heilderberg, 2013, págs. 395-420.

${ }^{75}$ AJA, Eliseo. Estado..., cit., pág. 87 y ss. Asimismo, el autor citado se refiere a los errores múltiples en la elaboración de la sentencia y a la debilidad del TC en aquel momento, en tanto no se había renovado la vacante por un magistrado fallecido, un magistrado recusado, tres con mandato vencido y prorrogado y otros cuatro se en- 
se expidió en una sentencia muy extensa a lo largo de 147 fundamentos jurídicos. Afirmó que carecían de eficacia jurídica interpretativa las referencias del Preámbulo del Estatuto de Cataluña a "Cataluña como nación» y a "la realidad nacional de Cataluña»; declaró la inconstitucionalidad y, por lo tanto, nulos determinados artículos y apartados del Estatuto; determinó que no eran inconstitucionales, "siempre que se interpreten en los términos establecidos en el correspondiente fundamento jurídico que se indica», diversos preceptos, es decir, que acudió a la técnica de sentencias interpretativas, por medio de la cual no se declara inconstitucional una norma a condición de que se interprete en determinado sentido; y, finalmente, desestimó el recurso de inconstitucionalidad sobre el resto de las cuestiones planteadas.

El TC se refirió específicamente a la naturaleza jurídica de los Estatutos de Autonomía en los fundamentos jurídicos 3 a 6 . Sobre el mismo, resaltó que si bien son normas que pueden ejercer funciones «materialmente» constitucionales, están subordinadas de todos modos a la Constitución. En efecto, señaló que los Estatutos de Autonomía «son normas subordinadas a la Constitución, como corresponde a disposiciones normativas que no son expresión de un poder soberano, sino de una autonomía fundamentada en la Constitución, y por ella garantizada, para el ejercicio de la potestad legislativa en el marco de la Constitución misma». Sostuvo que la Constitución, como norma suprema del ordenamiento, no admite normas iguales ni superiores, sino sólo normas que le están jerárquicamente sometidas en todos los órdenes. Admitió que si bien no faltan en ningún ordenamiento normas jurídicas que, al margen de la Constitución stricto sensu, cumplen en el sistema normativo funciones que cabe calificar como materialmente constitucionales, tal calificación no tiene mayor alcance que el puramente doctrinal o académico, que en ningún caso se traduce en un valor normativo añadido al que estrictamente corresponde a todas las normas situadas extramuros de la Constitución formal. Por otro lado, en cuanto a la ubicación de los Estatutos de Autonomía en el sistema de fuentes, sostuvo que se integran en el ordenamiento bajo la forma de Ley Orgánica, forma jurídica a la que los artículos 81 y $147.3 \mathrm{CE}$, reservan su aprobación y su reforma. «La Ley orgánica es, en definitiva, jerárquicamente inferior a la Constitu-

contraban a punto de finalizar su mandato. Sobre el papel desempeñado por el TC, ver también las críticas de BLANCO VALDÉS, Roberto L. «El futuro de la justicia constitucional en España. Tras la Sentencia sobre el Estatuto de Cataluña «, Claves de razón práctica, $\mathrm{N}^{\circ} 212$, mayo 2011, págs. 12-23. 
ción y superior a las normas infralegales dictadas en el ámbito de su competencia propia ${ }^{76}$.

Asimismo, el TC distinguió diversos contenidos de los Estatutos de Autonomía. Como se expuso anteriormente, en primer lugar, se encuentra el contenido "necesario», que está integrado por el minimum referido en su artículo 147.2 CE (denominación, territorio, organización institucional y competencias) y por las disposiciones que traen causa de mandatos constitucionales específicos, como, entre otros, el que exige la disciplina estatutaria del régimen de designación de los Senadores autonómicos (art. 69.5 CE). En segundo lugar, puede existir un contenido constitucionalmente "posible» de los Estatutos en virtud de previsiones constitucionales «expresas». La propia Constitución permite expresamente que los Estatutos cuenten además con un contenido adicional: el artículo 3.2 CE prevé que sean los Estatutos de Autonomía las normas que dispongan la eventual cooficialidad de otras lenguas españolas; y el artículo 4.2 CE los habilita para reconocer banderas y enseñas propias. En tercer lugar, el TC, como ya lo había señalado en una ocasión anterior ${ }^{77}$, expuso que el contenido constitucionalmente lícito de los Estatutos de Autonomía incluye tanto el que la Constitución prevé de forma expresa, «como el contenido que, aun no estando expresamente señalado por la Constitución, es complemento adecuado por su conexión con las aludidas previsiones constitucionales, adecuación que ha de entenderse referida a la función que en sentido estricto la Constitución encomienda a los Estatutos, en cuanto norma institucional básica que ha de llevar a cabo la regulación funcional, institucional y competencial de cada Comunidad Autónoma».

Sobre este último punto, el TC sostuvo que si bien el ordenamiento español se reduce a unidad en la Constitución, desde ella, y en su marco, «los Estatutos de Autonomía confieren al Ordenamiento una diversidad que la Constitución permite, y que se verifica en el nivel legislativo, confiriendo a la autonomía de las Comunidades Autónomas el insoslayable carácter político que le es propio». De esta forma, la primera función constitucional de los Estatutos de Autonomía radica «en la diversificación del Ordenamiento mediante la creación de sistemas normativos autónomos, todos ellos subordinados jerárquicamente a la Constitución y ordenados entre sí con arreglo al criterio de competencia. Respecto de tales sistemas normativos autónomos el Estatuto es norma institucional básica (art. 147.1 CE) ${ }^{78}$.

\footnotetext{
${ }^{76} \mathrm{FJ} 3$.

${ }_{77}$ STC 247/2007, de 12 de diciembre, FJ 12.

${ }^{78} \mathrm{FJ} 4$.
} 
Por otro lado, en lo que respecta a la distribución competencial en los Estatutos de Autonomía, el TC ha señalado que el Estatuto dota de competencias propias a la Comunidad Autónoma por él constituida y de la que es norma institucional básica. Por lo tanto, tiene una función de atribución competencial que define, por un lado, un ámbito privativo de normación y de ejercicio del poder público por parte de la Comunidad Autónoma, y contribuye a perfilar, por otro, el ámbito de normación y poder propio del Estado. Sin embargo, el TC pone claramente de relieve que el Estatuto no es una norma atributiva de las competencias del Estado. Mientras que las competencias estatales son siempre competencias de origen constitucional directo e inmediato, las autonómicas, son de origen siempre inmediatamente estatutario y, por tanto, sólo indirectamente constitucional.

Finalmente, cabe destacar que el TC señaló que sólo se encuentra al alcance de su función interpretativa de la Constitución -y por lo tanto inaccesible a cualquier legislador- la definición de las categorías y conceptos constitucionales, entre ellos la definición de las competencias ${ }^{79}$.

La doctrina no ha sido coincidente respecto a la sentencia citada. Algunos autores criticaron la actuación del TC, como ALBERTí ${ }^{80}$, APARICIO $^{81}$ y VINTRÓ ${ }^{82}$. Por el contrario, otro sector de la doctrina consideró oportuna la posición del Tribunal Constitucional en relación a la posición de los Estatutos de Autonomía en el sistema de fuentes y el modo en que interpretó la distribución competencial entre el Estado y las Comunidades Autónomas, como MUÑOZ MACHA-

${ }^{79} \mathrm{FJ} 6$.

${ }^{80} \mathrm{El}$ autor afirma que el TC no tuvo en cuenta que el Estatuto de Autonomía es una norma intermedia que resulta imprescindible para completar y configurar la distribución entre el Estado y las Comunidades Autónomas, operación cuya necesaria existencia expresa claramente un pacto político que no puede ser olvidado ni sustituido por el Tribunal (ALBERTÍ, Enoch. "Concepto y función del Estatuto de Autonomía2, Revista catalana de Dret Públic, 2010, págs. 81-85).

${ }^{81}$ Sostiene que en la sentencia el Tribunal Constitucional es un poder constituido y que no puede dar contenido alguno a la Constitución si la Constitución no tiene en sí misma ese contenido, haciendo desaparecer la función esencial del Estatuto de Autonomía (APARICIO, Miguel Ángel. "Algunas consideraciones sobre la STC 31/2010 y el rol atribuido al Tribunal Constitucional», Revista catalana de Dret Públic, Número Especial, 2010, págs. 23-28).

${ }^{82}$ Afirma que en definitiva, en todo el aspecto competencial, la deferencia del Tribunal Constitucional con respecto al legislador estatutario ha sido en los aspectos esenciales prácticamente nula, al situar al propio Tribunal Constitucional no como un controlador en última instancia sino como el intérprete "único», "auténtico»e «indiscutible» en este ámbito (VINTRÓ, Joan. "Valoración general de la STC 31/2010»", Revista catalana de Dret Públic, Número Especial, 2010, págs. 49-63). 


\section{DO $^{83}$, CANOSA USERA $^{84}$, BLANCO VALDÉS $^{85}$ y GARCÍA ROCA ${ }^{86}$, y de la QUADRA ${ }^{87}$.}

Por su parte, GARCÍA DE ENTRERRÍA y RAMÓN FERNANDEZ consideran que la STC 31/2010, ha corregido la referencia a un espacio competencial supuestamente «desconstitucionalizado» que permitiría a los Estatutos, según la STC 247/2007, asumir libremente competencias con el fin de completarlo, subrayando con toda claridad que los Estatutos no son expresión de un poder soberano, sino normas subordinadas a la Constitución y sometidas a ésta ${ }^{88}$.

${ }^{83}$ Destaca que la sentencia enseña que la Constitución no puede ser innovada a través de los Estatutos de Autonomía, sino que las normas constitucionales aplicables a la organización territorial del Estado, interpretadas largamente por el TC, tienen una densidad muy consistente y no pueden ser removidas mediante normas estatutarias para incrementar las atribuciones de una Comunidad o cambiar sus relaciones con los poderes del Estado (MUÑOZ MACHADO, Santiago. «El dogma de la Constitución inacabada», Revista Española de Derecho Constitucional, N 90, 2010, págs. 245-266).

${ }^{84} \mathrm{El}$ autor sostiene que el TC advierte con acierto que no cabe en los Estatutos definir el alcance de las competencias estatales, lo que hubiera producido una asimetría intolerable ya que, de lo contrario, las competencias estatales habrían tenido respecto de Cataluña una proyección diferente (CANOSA USERA, Raúl, "Encuesta sobre la STC 31/2010», Teoría y Realidad Constitucional, $\mathrm{N}^{\circ} 27,2011$, págs. 9-130).

${ }^{85} \mathrm{El}$ autor comparte con el TC que los Estatutos no puedan proceder a definir las categorías constitucionales. Sostiene que pueden atribuir competencias, pero lo que haya de entenderse por competencia y qué potestades comprenda son presupuestos del sistema reservados a la norma primera que lo constituye (BLANCO VALDÉS, Roberto. "Encuesta sobre la STC 31/2010», Teoría y Realidad Constitucional, N $^{\circ} 27$, 2011, págs. 9-130). Sin embargo, como fue señalado precedentemente, el autor ha criticado la labor ejercida por el Tribunal Constitucional en el caso.

${ }^{86}$ Sostiene que la parte de la sentencia relativa al tema competencial es técnicamente muy correcta, en tanto las competencias del Estado y de las Comunidades Autónomas son un objeto de naturaleza multilateral y deben ser reguladas por el titular de la competencia de competencias (GARCÍA ROCA, Javier. «Encuesta sobre la STC 31/2010», Teoría y Realidad Constitucional, N² 27, 2011, págs. 9-130).

${ }^{87}$ Asimismo, se refiere a que uno de los propósitos fundamentales que han animado a la reforma estatutaria catalana era el denominado «blindaje competencial», que implica un blindaje de competencias de la Comunidad Autónoma frente al riesgo de que el Estado al ejercer las suyas pueda afectar la capacidad de decisión autonómica. Sin embargo, afirma que si bien la configuración de algunas competencias estatales como amplios títulos de intervención, por ser títulos transversales u horizontales o ser títulos sobre lo básico, ha tenido repercusión sobre la capacidad autonómica de adoptar decisiones propias en el ejercicio de las competencias legislativas materiales atribuidas estatutariamente, resalta que ello no es más que una característica del sistema de distribución de competencias establecido por la propia Constitución, y no un defecto o vicio en la operativa o funcionamiento del mismo (QUADRA-SALCEDO JANINI, Tomás de la. «El Tribunal Constitucional en defensa de la Constitución. El mantenimiento del modelo competencial en la STC 31/2010, sobre el Estatuto de Cataluña», Revista Española de Derecho Constitucional, N. ${ }^{\circ}$ 90, 2010, págs. 287-334).

${ }^{88}$ GARCÍA DE ENTERRÍA, Eduardo; RAMÓN FERNANDEZ, Tomás. Curso..., cit. pág. 324 . 
En una postura contraria se encuentra AJA, quien sostiene que la sentencia utiliza una visión muy estrecha del Estatuto, insistiendo en la perspectiva de que es una Ley Orgánica, en vez de resaltar el carácter de norma pactada entre el Estado y la Generalitat, como el propio TC lo había sostenido en sentencias anteriores. Sostuvo a su vez que el Estatuto y la sentencia suponen un choque de trenes entre dos nacionalismos, el catalán y el español ${ }^{89}$.

Del mismo modo, GARRORENA MORALES critica la sentencia por considerar que ha insistido -innecesariamente y con exceso- en la idea de que los Estatutos no son Constitución porque «no son expresión de un poder soberano». Si bien afirma que es una idea que no puede negarse, considera que devalúa -aunque no lo ignore- la consideración de aquellos como normas que cumplen una función efectivamente constitucional ${ }^{90}$.

\section{CONCLUSIONES}

Muchos autores se refieren a España como un país que contiene diversas características de un país federal. Sin embargo, comparando al sistema autonómico español con el sistema federal argentino, si bien hay ciertos rasgos similares, lo cierto es que existen ciertas diferencias. Entre ellas, pueden destacarse las siguientes:

i. La primera diferencia que cabe destacar, lo que incidirá en la organización territorial, es que Argentina es caracterizada como una sociedad mononacional, mientras que España es presentado como un ejemplo de sociedad multinacional.

ii. Mientras que en el caso argentino las provincias son previas al Gobierno federal, conforme surge del Preámbulo de la Constitución establecida en 1853, en el caso español la propia Constitución trasladó a un momento posterior la concreción y el desarrollo de la autonomía territorial.

iii. En la organización territorial de la Nación Argentina se distinguen las provincias y los municipios, existiendo también el supuesto especial de la Ciudad de Buenos Aires. En España, el Estado se organiza territorialmente en Comunidades Autónomas, provincias y municipios.

${ }^{89}$ AJA, Eliseo. Estado..., cit., págs. 89-96.

${ }^{90}$ GARRORENA MORALES, Ángel. Derecho..., cit., pág. 229. 
iv. En Argentina, los gobiernos de provincia ejercen la potestad ejecutiva, legislativa y judicial, mientras que en España la función de administrar justicia es una competencia exclusiva del Estado central.

$v$. Las constituciones provinciales argentinas desde sus comienzos contuvieron declaraciones de derechos, debiendo estas adecuarse al sistema de derechos reconocidos en la Constitución. En España, los Estatutos de Autonomía los incorporaron expresamente en las últimas reformas y, sobre el punto, el TC los ha admitido siempre que no afecten la integridad de las competencias estatales.

$v i$. En Argentina, existe la cláusula residual, por la que los poderes de las provincias son originarios e indefinidos y los delegados a la Nación definidos y expresos. En España, la Constitución reconoce grados de autonomía, con distintos grados de competencias, existiendo mecanismos pasibles de reajustar excepcionalmente esa distribución, como es el caso de las leyes marco, las leyes orgánicas de transferencia y las leyes de armonización.

vii. En el Senado argentino las provincias están representadas de forma igualitaria, y los proyectos legislativos requieren de su aprobación para convertirse en ley. Por el contrario, en España no hay una representación igualitaria entre las Comunidades Autónomas en el Senado, y en el procedimiento de sanción de leyes termina prevaleciendo la voluntad del Congreso de los Diputados.

viii. En lo que respecta al financiamiento, la Constitución Argentina prevé un régimen de coparticipación que debe ser establecido por una ley convenio, que aún no ha sido aprobada. En España, se ha dicho que las normas constitucionales son pocas y muy genéricas, por lo que adopta gran relevancia la Ley Orgánica de Financiación de las Comunidades Autónomas, que es reformada aproximadamente cada cinco años.

ix. La Constitución Argentina prevé la intervención federal en las provincias para determinados casos excepcionales. En España, se establece un mecanismo de control subsidiario para situaciones excepcionales o extremas cuando las Comunidades Autónomas incumplan las obligaciones impuestas por la Constitución.

$x$. Por último, cabe resaltar las diferencias entre las constituciones de las provincias argentinas y los Estatutos de Autonomía, tanto en cuanto a su denominación, elaboración y el procedimiento de reforma. En efecto, en Argentina tanto en el procedimiento de elaboración como en el de reforma de las constituciones provinciales, no interviene el Gobierno federal. Por el contrario, los Estatutos de 
Autonomía requieren, para su elaboración y modificación, la concurrencia del Estado y de la respectiva Comunidad Autónoma.

Finalmente, cabe señalar que en España existen -en palabras de la Constitución Española- «nacionalidades» distintas e, incluso, lenguas diversas. La configuración de la división territorial de España efectuada en la Constitución de 1978, especialmente en su título VIII, si bien estableció un marco para el desarrollo de las diversas nacionalidades y regiones, se advierte que 35 años después se torna necesaria una reforma que reconozca la pluralidad existente y delimite adecuadamente las competencias entre el Estado central y las Comunidades Autónomas. Si bien la necesidad de la reforma se ha planteado tanto en ámbitos políticos como académicos, consideramos que sería conveniente debatir aspectos concretos a ser reformados y formular propuestas, y no mantenerse en un debate general sobre el tema. Esto se torna necesario para plasmar en la Constitución de forma definitiva la división territorial del Estado español y delimitar de una mejor manera las competencias del Estado y de las Comunidades Autónomas, a fin de mantener la unidad de España, sin desconocer su pluralidad. 